pp. $91-118$

\title{
INVESTIGACIONES SOBRE LAS PLANTAS MEDICINALES DE LOS SHIPIBO-CONIBO DEL UCAYALI
}

Jacques Tournon

U. Reátegui

After an Introduction on the Shipibo-Conibo term of "rao", which covers more than medicinal plants, the authors give an account of their investigations of the "rao" in three different communities. An analysis is done of their intra and inter-communal distributions and of their nomenclature. The inventory of the bundred and ten collected "rao", with the botanical identification of the majority of them as well as their uses and properties; is given at the end.

$$
\text { tr } x
$$

Les auteurs expliquent d'abord le terme Sbipibo-Conibo de "reo" qui a un champ sémantique plus large que celui de plante médicinale. Les "rao" ont été recueillis et étudiés dans trois villages indigènes. Leurs distributions intra et intercommunales sont analysées ainsi que leur nomenclature. L'inventaire des cent dix plantes étudiées, dont la majorité a été identifiée, est donnée en Annexe avec leurs usages et propriétés.

$$
\text { * * t }
$$

Nach einer einfübrenden Erklärung der hier angewandten Bezeichnung "rao", eines aus der Shipibo-Conibo Sprache stammenden Wortes, dessen Bedeutung den der Medizin Pflanze übertrifft, werden die intra und interkomunale Verbreitung und die Nomenklatur von "rao" aus drei verschiedenen Dörfern verglichen. Das. Verzeichnis der 110 untersuchten Pflanzen, die zum grössten Teil botanisch bestimmt sind, befindet sich, zusammen mit ibren Anwendungen und Wirkungen, in Anbang.

\section{DIGITALIZADO EN EL CENDOC - CAAAP}


Se hace cada día más evidente la importancia de estudiar la medicina tradicional y las plantas medicinales de los grupos nativos de la Amazonía peruana. Los recursos en plantas medicinales son inmensos y un mejor conocimiento de ellas y de sus propiedades farmacológicas podría permitir una nueva política de la salud con mejor planificación de los recursos económicos y naturales.

Este artículo trata de la medicina tradicional y de las plantas medicinales del grupo nativo Shipibo-Conibo. Se basa sobre un trabajo en tres comunidades de este grupo, escogidas por sus diferentes caracteres. La medicina tradicional de los Shipibo-Conibo ha sido poco estudiada, a pesar de ser el grupo más numeroso en el Ucayali, ocupando sus orillas desde Bolognesi hasta Contamana, y de tener una importancia económica y cultural de primer plano en todo el Departamento de Ucayali. Sin embargo con respecto a nuestro estudio debemos mencionar un capítulo del libro de Eakin et al. (1980) que da una lista de solamente 25 plantas medicinales con varias determinaciones falsas, ej. Allium satirum (sic) para el "buens".

Cuando un informante Shipibo-Conibo designa una planta medicinal, él agrega la palabra "rao" al nombre específico de la planta. Así, en nuestras primeras encuestas creíamos que los dos términos "rao" y "planta medicinal" eran equivalentes, pero al consultar el Diccionario Shipibo-Conibo de F.N. Guillén (1974), tuvimos la sorpresa de ver el término "rao" traducido por "veneno". Advertimos así que este término tiene un campo semántico amplio que incluye a: plantas medicinales, venenos, plantas para pescar (cebos, estupefacientes), para cazar (para encontrar animales, acercarse a ellos, atraerlos, tener buena puntería), plantas para controlar personas o seducirlas ("puzangas"), plantas mágicas para protegerse de los espíritus, plantas alucinógenas y psicotrópicas. Todas esas plantas tienen un poder, spb. "coshi". Entonces no estudiamos solamente las plantas medicinales sino que extendimos nuestra investigación a todos los "rao". El mundo vegetal de los Shipibo-Conibo se puede dividir en "rao" y "raoma" ("ma" es el sufijo de negación); es decir que la planta pertenecerá a uno u otro grupo si tiene o no un "coshi". Para precisar si esa planta es medicinal 'o venenosa los nativos agregan el adjetivo "jacon" (bueno) o "jaconma" (malo). Así una planta medicinal será "rao jacon" y un veneno "rao jaconima". Pero los nativos son concientes del carácter arbitrario de ese adjetivo, pues un "rao" puede ser "jacon" o "jaconma" según el uso que se haga de la planta y su dosis. La propiedad esencial de la planta es la existencia de un "coshi" y no de su índole positiva o negativa. Así, el catahua, spb. "ana" (Hura crepitans) tiene un "coshi" muy fuerte y puede ser utilizado para curar la uta (Leishmania brasiliensis), para entorpecer pescados o para matar a enemigos.

En el mundo de los Shipibo-Conibo cualquier ser viviente, animal o vegetal, e incluso sitios, lugares y accidentes topográficos, como los "maya" (remolinos y meandros de un río), "mana" (lomas y cerros) tienen un "yoshin" (espíritu, traducido por los misioneros por diablos o demonios)., Entonces tanto "rao" como "raoma" tienen su "yoshin"; pero los "rao" tienen un "yoshin coshi", un espíritu con poder. Por ejemplo el "ana" (Hura crepitans) tiene un "yoshin coshi", es un "rao", pero el "tahua" (Gynerium sagitatum) tiene un "yoshin coshima", pues es un "raoma". En el mundo de los Shipibo-Conibo los "yoshin" no son solamente conceptos sino que también son operativos. Así los "yoshin" de los cerros y de los remolinos pueden "copiati" (pegar, enfermar y en el castellano local "cutipar") a los viajeros que se acercan a ellos, "mana yoshin nihue bia" que traducimos por "él recibió el aire del 
Ubicación de Comunidades Shipibas mencionadas en el texto.

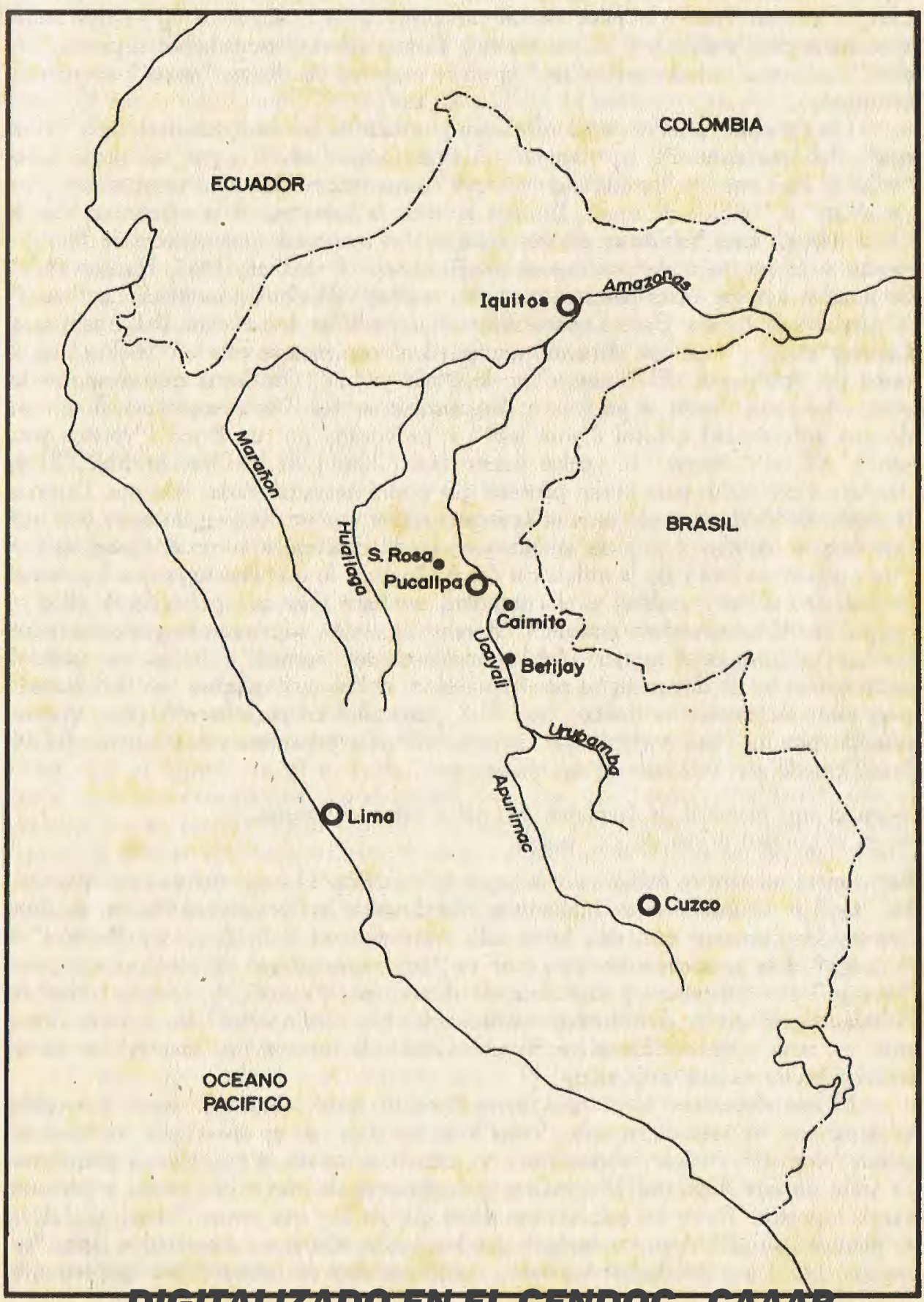


espíritu del cerro". Para proteger a su niño de esos espíritus, la madre sobará su cuerpo con un "rao": la papa de un piri-piri, "uaste", (Cyperus sp.) o las frutas aromáticas del "yoshin bia" (Siparuna sp.). Comer ciertas carnes también puede "co. piati", así como tomar ciertos "rao" si no se respetan las dietas ("sama") necesarias, cf. infra.

Los "yoshin" pueden ser controlados y utilizados por un curandero (spb. "onanya": "el que conoce") o "raomis" (el experto en "rao") o por un brujo (spb. "yobe"). Para ver los "yoshin", el "onanya" toma una bebida alucinógena, spb. "nichi-shiati" o "bebida de soga", llamada en toda la Selva por el nombre quechua de "Ayahuasca". Esta bebida se obtiene siempre del tronco de una especia de Banisteriopsis y de las hojas de una especie de Psychotria (Friedberg 1965, Harner 1973). Se pueden agregar otras plantas como la "marosa" (Pfaffia irisinoides), un "uaste" (Cyperus sp.) o una Datura, para reforzar o modular los efectos del Ayahuasca. Ciertos "onanya" nos han afirmado que pueden comunicarse con los "yoshin" $\sin$ la toma del Ayahuasca. El "onanya" ve los "rao yoshin", los llama uno después del otro, ellos vienen a ver al paciente y diagnosticar su mal. Por ejemplo ven si se trata de una enfermedad natural ("yora isin") o provocada por un brujo ("yobeca yora isin"). Así, el "onanya" se vuelve dueño (spb. "ibo") de los "rao yoshin". El va después a utilizarlos para curar, proceso que podrá necesitar varias sesiones. Durante la sesión de Ayahuasca el "onanya" canta con una voz especial en un tono más alto que su voz habitual y a veces en idiomas que él desconoce como el Quechua y el Piro cuando no está bajo la influencia del Ayahuasca; lo que ocurre es que los cantos vienen de los "rao yoshin" y el curandero no hace más que prestarles a ellos su propia voz. Un curandero nos dijo: "durante la sesión soy como la grabadora, son los rao yoshin quienes cantan". Así las relaciones del "raomis" y de los "rao yoshin" están marcadas de dos maneras por la posesión: el "raomis" emplea los "rao yoshin" para curar, se vuelve su dueño, "rao ibo", pero también para hacerlo tiene que ser poseído por los "rao yoshin" que usan su voz para expresarse. Así, vemos que un "rao" puede ser utilizado de dos maneras:

- en el uso material de la planta por vía externa o interna, - en el control y usó de su "yoshin".

La primera manera es exotérica y la segunda esotérica. El conocimiento exotérico de los "rao" es difundido entre numerosos miembros de la Comunidad Nativa, en cambio su conocimiento esotérico lo es sólo entre algunos individuos: los "raomis" o "onanya". Ese conocimiento pasa por un largo aprendizaje del discípulo con un "onanya" ya confirmado y una serie de dietas, spb. "sama" cf. "infra, y tomas de bebidas alucinógenas. En muchas comunidades hay un "onanya", en algunas dos o más, en otras ninguno. Entre los Shipibo-Conibo la función de "onanya" no es remunerada, no es una profesión.

El uso de varios "rao" que tienen "yoshin coshi", espíritus poderosos, debe acompañarse de una dieta, spb. "sama". Si esa dieta no es observada, el "yoshin" puede "copiati", cutipar, al paciente y su estado se agravaría en lugar de mejorarse. Se trata de una dieta parcial que hay que observar de uno a dos meses y presenta varios aspectos. Todos los informantes dicen que no hay que tomar "ni sal, ni dulces, ni manteca, ni aji". Algunos agregan que los únicos alimentos autorizados (spb. "samaquin piti") son productos vegetales, carnes de aves de monte como: perdiz, spb. 
"conma" (Tinamus sp.), paujil, spb. "hasin" (Mitu mitu), pucacunga, spb. "quebo" (Cracideas) y peces de carne sin grasa como el boqui chico, spb. "bohue" (Prochilopus amazonensis), las sardinas (Engraulis iquitensis). Las carnes de monte y pescados deben ser cocidos sin grasa, hervidos, al vapor o en "patarashca", es decir entre hojas de bijao, spb. "mani" (Heliconia cannoides). El paciente que dieta debe abstenerse de relaciones sexuales y dejar su domicilio familiar para permanecer en un tambito (spb. "peota") aislado, donde un(a) muchacho(a) del mismo sexo le traerá su comida. Los "rao" que necesitan una dieta son plantas que se toman en bebidas y los indicamos en el inventario.

En este trabajo presentamos a las tres comunidades donde hicimos el estudio, analizamos la distribución de los "rao" según su medio dentro de cada comunidad (Distribución intracomunal) y después entre las tres comunidades (Distribución intercomunal). Indicamos después la posición de los "rao" en el mundo vegetal de los Shipibo-Conibo y ciertos aspectos de la nomenclatura de los "raó". Además damos términos nativos que designan las diferentes afecciones sobre las cuales los "rao" tienen efecto terapéutico. El inventario se ofrece al final del texto.

\section{A. COMUNIDADES ESTUDIADAS}

El grupo Shipibo-Conibo vive en una zona muy extensa de diferentes características geográficas y ecológicas. Vamos a exponer y analizar los datos recogidos en tres lugares representativos.

$1^{\circ}$ Betijay. Está ubicada sobre una terraza de la orilla izquierda del Ucayali, como la gran mayoría de las aproximadamente cincuenta comunidades Shipibo-Conibo. Las casas están a algunos cientos de metros del río y paralelos a él. Betijay es la comunidad más meridional y lejana de Pucallpa. Con "peke-peke" se necesitan de cinco a siete días para surcar de Pucallpa a Betijay, y para bajar, de tres a cinco días. Así, Betijay está sometida a menos influencias de Pucallpa que las comunidades ubicadas más àl Norte. En el invierno, estación de las lluvias, "jenetian”, el Ucayali crece de seis a siete metros. "En el verano, estación seca, "baritian" ("bari": sol), el río deja en su merma grandes playas de aluvión, los barrizales, de alta fertilidad, donde se cultivan de Mayo a Octubre plantas como: arroz (Oryza sativa), maní (spb. "tama", Arachis hypogea), 'chiclayo (Vigna unguiculata). Del otro lado de las casas están las chacras, donde se cultivan: frijol ("poroto", Phaseolus sp), yuca (spb. "atza", Manihot esculenta), maíz ("shequi", Zea mais), plátano ("pajanta", Musa sp.), piña (spb. "cancan", Ananas comosus) y otras frutales. La pesca en el Ucayali y la cocha $^{* \star}$ vecina es excelente en la estación seca y difícil cuando el río está' alto. En cambio la caza se vuelve más fácil en la estación de las lluvias, pues los animales de monte se agrupan en las áreas que se quedan secas: las "restingas".

$2^{\circ}$ Caimito. Caimito está ubicada sobre la laguna Imiría (spb. "imi": Pistia stratoides, Aracea) que se comunica con el río Tamaya afluente derecho del Ucayali. Esta laguna crece sólo de dos a tres metros en el invierno. Las tierras de esta zona no aprovechan los aluviones de los Andes, no hay los barrizales fértiles de las orillas del Ucayali. Los cultivos se hacen solamente en chacras ("huai"). Alrededor de Cai-

\footnotetext{
* "peke-peke": término regional utilizado para designar a canoas con motor fuera de borda.

** "cocha": término Quechua para designar laguna, es utilizado en todo el Perú.
} 
mito existen importantes zonas de purma ("nahue"). El sitio de Caimito fue ocupado desde tiempos antiguos como lo atestiguan la existencia de cerámicas de dos mil años de antigüedad. En los años cincuenta quedaron unas pocas familias, cuando llegaron familias de Caco y de San Francisco de Yarinacocha. En las orillas de la misma laguna hay dos Comunidades Shipibo-Conibo más: Junín Pablo y Nuevo Loreto; las familias de las tres Comunidades están vinculadas.

Betijay y la laguna Imiría están ubicadas en la zona de vegetación llamada "Bosque Seco Tropical" en la clasificación de Joseph Tosi (1960).

$3^{\circ}$ Santa Rosa de Agriaytía. Esta comunidad está ubicada sobre el alto río Aguaytía que baja de la Cordillera Oriental hasta el río Ucayali. Esta Comunidad fue fundada en los años cuarenta a partir de la antigua Comunidad de Nuevo Edén del alto río Pisqui. Un grupo de "Pisquibo" decidieron independizarse de sus "patrones" y se establecieron sobre el alto Aguaytía a algunas horas de "peke-peke" de la carretera de Lima a Pucallpa en construcción en aquel tiempo. El sitio de Santa Rosa había sido ocupado antes, como lo atestiguan hachas de piedra, probablemente por nativos Cashibo-Cacataibo (familia lingüística Pano) que ocupan todavía el río un poco más arriba de la Comunidad.

Santa Rosa está ubicada en la zona "Bosque muy Húmedo Premontano Tropical" según la clasificación de Joseph Tosi (1960).

\section{B. DISTRIBUCION DE LOS "RAO"}

$1^{\circ}$ Distribución intracomunal. El hombre Shipibo.Conibo tiene diferentes tipos de relación con las plantas en general y los "rao" en particular, que podemos distinguir por el grado de dependencia de la planta con él. Por un lado encontramos las plantas que se cultivan; por el otro, las plantas que se cosechan en un medio más o menos perturbado por el hombre. Distinguimos tres categorías:

Plantas cultivadas (spb. "vana rao"). La mayoría de estas son plantadas o sembradas alrededor de las casas, a menos de cincuenta metros de ellas, en un espacio limpiado regularmente de la maleza. Allí se encuentran las diferentes "uaste" (piripiri, Cyperaceas), la "malva" (Malachra capitata), la "viribina" (Verbena cf. brasiliensis), la "arbaha" (Ocimum sp.), el "paico" (Chenopodium ambrosianum), el "buens" (Petiveria alliacea) y otras (ver el inventario), todas plantas muy comunes. En cambio, muy pocos "rao" son cultivados en las chacras; citamos el caso de "nichicon" o ayahuasca (Banisteriopsis sp.).

Plantas de purma (spb. "nabua rao"). En esta categoría incluimos los "rao". que no son cultivados pero que aprovechan los espacios creados por el hombre, crecen en las purmas (spb. "nahue") y también invaden las chacras, caminos y otros espacios antrópicos. A veces no solamente aprovechan de esos espacios sino también en algo del cuidado del chacarero quien evita cortar los "rao" cuando limpia la maleza, pero esas plantas se reproducen sin la ayuda del hombre (de Wet, 1975).

Plantas del monte (spb. "nii rao"). Son los "rao" que viven en el monte, medio muy poco perturbado por el hombre desde hace decenas de años. Después de cincuenta años el monte secundario apenas se distingue del monte primario.

Con el fin de analizar la distribución de los "rao", los contamos en cada uno de los tres lugares estudiados: Betijay, Caimito y Santa Rosa de Aguaytía. En cada Comunidad distinguimos las plantas pertenecientes a cada categoria: cultivadas, de 
purma y de monte. En el cuadro anexo los números están representados en los cuadros "diagonales". Los números totales de "rao" recogidos en Betijay y Caimito son equivalentes (42.y 48), pero claramente inferiores en Santa Rosa de Águaytía (27). Varias explicaciones son posibles. Santa Rosa fue fundada por una migración de nativos de Nuevo Edén del Pisqui y es posible que los conocimientos sobre los "rao" se hayan perdido en el proceso. Otra explicación sería una diferencia entre las Floras del Alto Aguaytía y del Alto Pisqui, ya que "rao" espontáneos sobre el Alto Pisqui no lo son sobre el Alto Aguaytía. Podemos admitir que los "rao" de purma y de monte no son transportables o lo son difícilmente, al contrario de los "rao" cultivados. Así, deberíamos encontrar una proporción más baja de los primeros en Santa Rosa de Aguaytía. El cuadro anexo nos enseña que no es el caso, ya que los procentajes de "rao" de diferentes categorías son equivalentes en las tres comunidades. Otra posibilidad sería que varios "rao" se hayan perdido esos últimos años, ya que la proximidad de la carretera principal Lima-Pucallpa somete a la Comunidad de Santa Rosa a numerosas influencias culturales y económicas y produce una decul-

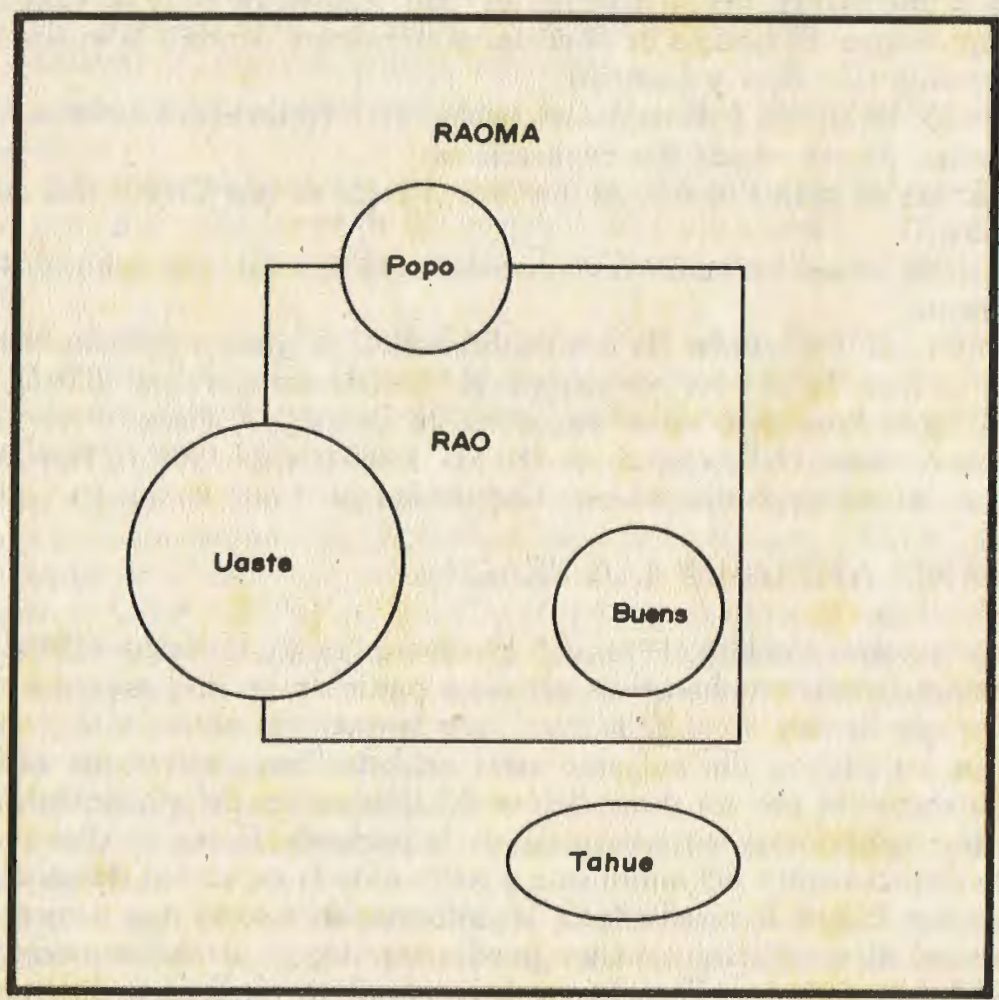

Esquema del mundo vegetal Shipibo-Conibo dividido entre "rao" y "raoma" 
Jacques Tournon y U. Reátegui

turación general. Esa explicación es consistente con la pérdida de "rao" de las tres categorías. Un resultado espectacular es que los porcentajes de "rao" en cada categoría son muy próximos para las tres Comunidades, con un poco más de plantas de purma en Caimito, a pesar que las tres Comunidades están ubicadas en zonas distintas y diferentes por sus caracteres ecológicos. Esa constancia parece reflejar el modo de vivir de los Shipibo-Conibo en relación con su ambiente vegetal y sería interesante comparar esos resultados con datos de otros grupos étnicos como los Cashibo-Cacataibo y los Campa que son grupos "interfluviales" (Meggers 1971, d'Ans 1982).

$2^{\circ}$ Distribución intercomunal. Es interesante comparar los "rao" conocidos a la vez en dos Comunidades. Los cuadros no-diagonales del mismo cuadro nos dan estas informaciones. Podemos ver en seguida que la gran mayoría de los "rao" comunes a dos Comunidades pertenecen a la categoria "Plantas cultivadas", los porcentajes son: $73 \%$ entre Betijay y Caimito, $91 \%$ entre Caimito y-Santa Rosa, $100 \%$ entre Betijay y Santa Rosa. Los "rao" de purma y monte que se encuentran en dos Comunidades son muy pocos: 3 entre Caimito y Betijay, 1 entre Caimito y Santa Rosa y ninguno entre Betijay y Santa Rosa. Hay que notar que esas dos últimas Comunidades son las más distantes y diferentes. En cuanto a los "rao" conocidos en las tres Comunidades estos son todos cultivados. Tenemos una evidencia de que hay un pequeño grupo de "rao" que se han difundido en toda la zona ocupada por los Shipibo-Conibo, eso demuestra la importancia del intercambio de "rao" cultivados entre las Comunidades de ese grupo étnico. El estudio de la cerámica demuestra también la importancia de este intercambio (De Boer y Lathrap).

Los "rao" de purma y de monte en cambio parecen limitados a ciertas Comunidades o zonas, de eso vemos dos explicaciones:

- las plantas de purma (o monte) que crecen cerca de una Comunidad no crecen en otra,

- las plantas crecen en varias Comunidades pero sus usos son conocidos en una solamente.

Creemos que son válidas las dos explicaciones, ya que no pudimos ver ciertas plantas de un lugar en el otro, por ejemplo el "Bonafousia undulata" (80-41) es muy común en Santa Rosa pero no se encuentra en Betijay y Caimito. Pero vimos en Betijay plantas como: Heliotropium sp. (80-31), Ludwigia sp. (80-22), Euphorbia sp. (80-28) que no son empleadas en esta Comunidad pero que lo son en. Caimito.

\section{NOMENCLATURA 'DE LOS "RAO"}

Varios autores: Conklin (1954), Cl. Friedberg (1970), C. Sastre (1980) analizaron las nomenclaturas etnobotánicas nativas a partir de las mạ́s pequeñas unidades taxonómicas que llaman "tipos de plantas", son las menores unidades vegetales reconocidas por los nativos. Sin embargo estas unidades taxonómicas son difíciles de obtener en encuestas por ser dependientes del informante, del etnobotánico y también de las condiciones y circunstancias de la encuesta. Como lo dice C. Sastre: "según los conocimientos del informante y sobre todo la capacidad del etnobotánico de comprender lo que le es enseñado, las informaciones serán más o menos precisas". Entonces el etnobotánico nunca puede estar seguro de haber encontrado la menor unidad taxonómica. Por esto preferimos utilizar el término de "nombre de base", que definimos como la menor unidad lexical que puede designar una planta. 
Ese nombre de base puede corresponder en la Botánica Científica de Linnéo a una especie, un género, una familia o un conjunto de estas unidades. Cuando el nombre de base designa solamente la planta y no tiene otro sentido, es un "nombre botánico", pero a veces tiene otro sentido en el idioma nativo (ej. "cashi tahue": garras de murciélago). El nombre de base puede ser simple, compuesto de una sola palabra ("uaste"), o compuesto de varias palabras ("cashi tahue"). El informador puede dar más precisión a ese nombre de base agregándole un determinante ("hasin uaste": "rao" de la serie de los "uaste").

$1^{\circ}$ Nombres botánicos. Inventariamos veintidós nombres botánicos. Esos nombres pueden ser muy precisos, correspondiendo a una sola especie de la Botánica Científica de Linnéo. Cítamos:

"au": Anthodiscus Klugii (Caryocaracea)

"semen". Calliandra angustifolia (Leguminosa)

Otros nombres pueden corresponder a varias especies pertenecientes a un mismo género:

"popo", varios Solanum fueron designados así:

"popo ani" de "ani" = grande, el Solanum grandiflorum,

"topopo" de "toti" = embarazada, el Solanum mammosum,

"popo" designa también un "raoma", el Solanum quitoense con frutas comestibles llamado en castellano local: "cocona", En el género "Solanum", "popo" parece designar solamente las especies leñosas, arbustivas.

Otros nombres designan plantas de varios Géneros de la Botánica Científica y hasta otras familias:

"Buens", a la fecha encontramos trés especies que se llaman así, son todas "rao" que tiene en común un olor fuerte de ajo pero que tienen morfología muy diferente. Dos especies pertenecen a la familia de las Bignonáceas y son "nii rao" ("rao" del monte):

Pachyptera standleyi, que los ribereños llaman "ajo sacha hembra", crece primero como un arbusto y después como soga; puede alcanzar grandes tamaños. Pseudocalymna alliaceum, llamado por los ribereños "ajo sacha macho", es un arbusto que no crece más que uno o dos metros.

La tercera especie es una "vana rao", "planta cultivada" muy común, que no crece más que cincuenta centímetros: Petiveria alliacea (Phitolacacea). "Uaste", ese nombre designa numerosos "rao" que pertenecen todos a la familia de los Cyperáceas, géneros: Cyperus, Eleocharis, Fuirana y un "rao" perteneciendo a la familia de las Iridáceas: Eleutherine bulbosa. Esos numerosos "uaste" son distinguidos por determinantes que en general indican su uso terapéutico, damos unos ejemplos, en español local. El "uaste" se llama "piri-piri":

"tobi uaste": piri-piri para lisiados,

"shea uaste": piri-piri para engordar,

"uashmon uaste": piri-piri de algodón, porque se pone sobre el ombligo de la criatura como algodón,

"bohue uaste": piri-piri de "boqui chico", nombre en castellano local del pescado Prochilodus amazonensis, con la papa de ese piri-piri se soba la flecha de pesca; "repoti uaste": de "repoti" = "poner en la nariz", en ese caso el determinante alude al modo de empleo. 
En el caso de la Eleutherine bulbosa", Iridacea, que se llama "basin uaste", el determinante describe el color rojo de la papa como la cresta del paujil, spb. "basin", oro. Mitu mitu: también podría aludir a su uso terapéutico pues es empleado para curar hemorragias.

Esos "uaste" son todos cultivados, son "vana rao", y se propagan por los rizomas y tubérculos. Los numerosos "uaste" que son Cyperus son difíciles de distinguir para los botánicos, son variedades reproducidas por sus tubérculos. Además de esos "vana uaste", piri-piri cultivados, hay "uaste" que son silvestres o crecen en lugares pantanosos y no son medicinales, son "raoma".

B. Berlin (1979) estudió la Taxonomía entre los Aguaruna y mostró que los "taxas" o "categorías genéricas" en ese grupo nativo "corresponden estrechamente a los taxas de los géneros y especies reconocidos por la Botánica Occidental". Examinemos la situación entre los "rao" de los Shipibo-Conibo. Los "popo" corresponden bien a lo que observó Berlin entre los Aguaruna, pertenecen solamente al género Solanum y en ese género a los arbustos leñosos. Los "uaste" corresponden a cuatro géneros y dos familias, sin embargo las Cyperáceas de lo géneros Cyperus, Eleocharis y Fuirana presentan grandes semejanzas en su morfología, solamente la Eleutherine bulbosa ("hasin uaste") tiene un aspecto bien diferente debido a su bulbo y hojas y sobre todo su inflorescencia. Hay que observar que es el único "uaste" que tiene en su denominación un determinante que no designa el uso terapéutico sino su apariencia: alude al color rojo-carmín del bulbo como el de la cresta del paujil, spb. "hasin" (Mitu mitu). Con respecto a los "buens": son plantas que tienen en común su olor alliáceo pero no tienen ninguna semejanza y pertenecen a tres géneros y dos familias diferentes.

Esos ejemplos enseñan que los Shipibo-Conibo pueden emplear criterios de diferentes naturalezas para la nomenclatura de sus "rao", por ejemplo el aspecto, el olor, el empleo, y que esos criterios pueden ser estrechos (caso del "popo") o amplios (caso de los "uaste"). Nuestras observaciones de la nomenclatura etnobotánica de los Shipibo-Conibo, todavía limitadas a los "rao", son más como las de Sastre con los Boni que como las observaciones de Berlin con los Aguaruna. También es interesante notar que los "buens" son todos "rao" pero que los "uaste" y los "popo" pueden ser "rao" o "raoma". Eso esta resumido en el esquema anexo del mundo vegetal de los Shipibo-Conibo, dividido en dominios "rao" y "raoma". En ese esquema ciertos taxa como el "buens" están completamente en el dominio "rao", otros como el "popo" y el "uaste" están a la vez sobre los dominios "rao" y "raoma", el tercer caso es el de los "tahura", cañas, (Gynerium sp.) que son enteramente del dominio "raoma".

$2^{\circ}$ Nombres no-botánicos. Muchas veces el informante no conoce un nombre botánico: designa el "rao" por su uso terapéutico o por algunos caracteres notables; a veces también alude a un animal al cual la planta está asociada por un mito.

Nomenclatura terapéutica. Encontramos varias plantas llamadas "tobi rao", de "tobi" = lisiado, que se ponen como un emplasto alrededor del miembro lisiado. Son todas plantas succulentes que pertenecen a varias familias (Crassulaceas, Cactaceas). Citaremos otros usos que designan "rao":

"Hivuin rao": "rao" de la raya (Potamotrygon hystrix), es un Heliotropium, Familia Borraginacea. Se echa el jugo de la planta sobre la herida hecha por la raya.

"Marica mishquitinin rao" (Justicia pectoralis): "marica" es un nombre que parece designar varias plantas, "mishquitinin" significa anzuelar, es un "rao" para pescar. 
"Shobi isa sheta" (Bidens pilosa): "shobi" = hierba, "isa" es el término general para pájaro, "sheta" = diente. Ese "rao" se emplea contra el mal de diente.

"Chiquish payati" (Cyphomandra sp.): "abanica la pereza", para el mal de cabeza y "falta de ánimo para trabajar".

En otros casos el nombre alude al modo de empleo más que al objetivo terapéutico: "Nane repote" (Bonafousia longituba): "nane" = huito (Genipa americana), "repote" $=$ poner en la nariz.

Nomenclatura descriptiva. A veces el informante describe el "rao" de manera muy sumaria, lo designa solamente por los términos: "shobi" = hierba, "bibui" = árbol, "nichi" = soga, pero la descripción puede ser más completa:

"Ino paviqui" (Acantacea) = "oreja de tigre", su hoja es velluda y carnosa como la del tigre, y también crece en el monte.

"Cashi tae" (Macfadyena unguiscati), los garfios de esa soga parecen garras ("tae") de murciélagos ("cashi").

"Iscon ratonco" (Rubiacea) = "rótula de paucar", orn. Icteridaea.

El nombre puede caracterizar un olor:

"Rimon ininti" (Justicia sp.) = "olor de limón".

"Inin tani" (Bignonacea) = "huele un poco".

"Pisi sisa" (Tagetes sp.) = "flor que apesta", de "pisi" = apestar y "sisa" = flor en idioma Quechua.

En algunos casos el nombre alude a un sabor:

"Muca pari" (Bonafousia undulata), "muca" designa sabores fuertes como lo del alcohol y los amargos.

"Vona muca" (Strychnos sp.), "vona" = isula, "muca" = amargo, fuerte.

Encontramos dos nombres que aluden a propiedades mecánicas de la planta:

"Nepa" (Scleria mitis) = "que corta" y "Shobi shodish" (Sida sp.) = "hierba dura".

Referencia a un mito. Encontramos nombres de plantas que aluden a nombres de animales. La referencia no parece basada en una apariencia con el animal mencionado y la vinculación entre el "rao" y el animal sino que más bien parece aludir a un mito. Citamos cuatro casos donde el animal es un pájaro:

"Chono ininti" (Justicia sp.) = olor del "chono", pájaro del género Hirundinae. "Pish-pish" (Convolvulacea), "hay un ave que canta pish-pish, antes esta ave se curaba con esa planta", "pish-pish" designa pequeñas aves del género Tachyphonus, familia de los Thraupidae.

"Mai caua rao" (Ocimum gratissimum), el ave "mai caua" es un ave de rapiña, familia de las Accipitriae, "su grito es mai caua", "mai" = tierra, "caua" = envolver. "Caya nari rao" (Ludwigia sp.), el ave "caya nari" es el Leucopternis cayanensis (Accipitridae), "caya" = sombre o espíritu. "Esa planta es el remedio de este pájaro, la llamamos también "caya nari mucha" porque es empleada para cazar o pescar, "mucha" significa cazador o pescador.

Así, en tiempos míticos los pájaros empleaban "rao". Mencionamos que un mito fue recogido de un "rao" que permitía volar (Loriot, 1970).

Terminamos con el caso del "ronon rao" que usa varias referencias. "Ronon" designa a aquellas serpientes llamadas en castellano local "jergón" (Bothrops sp.). Ese "rao" corresponde a una o varias especies del género Dracontium (aracea), su tallo es manchado como la piel del jergón. Para evitar el ataque de esta serpiente se 
azotan las piernas con él; para curar su mordedura se pone la papa raspada, y se dice que "donde crece, vive el jergón".

Nombres Importados, Varios nombres son de origen extranjero. Citaremos unos de origen castellano:

"Pion" (Jatropha sp.) de "piñon".

"Viribina" (verbena cf. brasiliensis) de "verbena".

"Arbaha" (Ocimum sp.) de "albahaca".

"Menta" (Mentha sp.) de "menta".

Esas plantas pertenecen al núcleo de plantas cultivadas que, como lo mostramos más arriba, se encuentran en las tres comunidades estudiadas. Son plantas cosmopolitas y se puede pensar que ellas fueron llevadas por los españoles. Si examinamos sus orígenes vemos que los Jatropha son de origen centro-americano (Croat, 1978), en cuanto a las Verbena, Ocimum y Mentha hay especies del viejo y del nuevo mundo. El nombre de "Sanango" podría venir del castellano sanar pero también del quechua: "sana" = signo, designa entre los ribereños plantas de diferentes géneros y entre los Shipibo-Conibo varias especies de Bonafousia: B. sananho, B. longituba, B. tetrastachys y a veces el B. undulata (llamado también en Santa Rosa de Aguaytía "muca pari").

"Paico" (Chenopodium ambrosianum) se encuentra en el Diccionario de D.G. Holguin como "hierba medicinal de comer".

\section{TERMINOLOGIA ETNOMEDICINAL}

En nuestras encuestas sobre los "rao" anotamos los términos en idioma Shipibo-Conibo que designan los usos terapéuticos. Son términos que indican ciertos dolores o algún "mal", y en consecuencia son los primeros elementos de una Sintomatología nativa. La Nosología y la Etiología nativas están todavía por ser estudiadas. Dos palabras significan "olor" y "mal" en general, son "tisha" y "isin", ellas se emplean en composición, así notamos con "tisha":

"Mapon tisha" o "bushcaten tisha" para "mal de cabeza".

"Pocon tisha" para "mal de barriga".

$Y$ con "isin":

"Shate isin" para el dolor de una herida.

"Shochi sicho isin" para dolor de pecho.

"Oco isin" para la tos.

Sería interesante conocer mejor los campos semánticos de los términos.

Citamos otros términos empleados con frecuencia:

"Tichotai" para la diarrea, de "tich" = anus.

"Quinanai" para el vómito.

"Pequeta" para una infección.

"Nohue" para un chupo.

"Yona" para fiebre.

"Seya" para comezón.

"Pushnon" para roncha. 


\section{E. INVENTARIO DE LOS "RAO"}

En el anexo hay un inventario de ciento diez "rao". Esas plantas recogidas por los autores en las tres Comunidades descritas fueron determinadas y tipificadas sobre la base de muestras que forman el Herbario de referencia en el cual cada una tiene un número compuesto de las dos últimas cifras del año de recolección y de un número de referencia en el año: por ejemplo 77-15 ó 81-44. Entre esas plantas, ciento una fueron determinadas por lo menos en el nivel de la familia botánica, ellas son clasificadas por familia y las familias están en orden alfabético, después siguen el Género y la Especie.

Luego hicimos una breve descripción de la planta, de su origen, de su medio. Anotamos sus nombres en idioma Shipibo-Conibo y en castellano regional ("nombre común"). La terapéutica está anotada en la lengua de los informantes cuando se expresan en castellano de la región o son traducidos de los terminos nativos que mencionamos más arriba. Es decir que no escribimos las acciones de cada "rao" en el lenguaje de la Farmacología occidental, pues faltan los estudios farmacológicos sobre la mayoría de los "rao".

\section{CONCLUSION}

A pesar de los éxitos en la lucha contra varias enfermedades epidémicas, debido a campañas de vacunación, la salud de los Shipibo-Conibo es todavía precaria. Los parásitos afectan a toda la población y causan una alta mortalidad infantil, la tuberculosis afecta más o menos al veinte por ciento de la población. Muchas comunidades nunca han visto ningún médico. En demasiados casos la asistencia médica de las misiones "religiosas" y "filantrópicas" se hacen sin buenos criterios y métodos científicos y aumentan la dependencia de las comunidades con el exterior. Además los misioneros con sus hábitos de ver demonios y diablos en los "yoshin" y "onanya" sin tratar de comprender las concepciones nativas del mundo, destruyen la confianza de los Shipibo-Conibo en su propia medicina tradicional y los hacen dudar de su propia cultura y dignidad. En cambio deseamos que este trabajo sea un paso adelante en la comprensión de la medicina tradicional de los Shipibo-Conibo, pero estamos conscientes que este presenta solamente unos aspectos de esa medicina y que mucho queda por investigar. Ciento diez "rao" están inventariados pero sin duda muchos quedan por serlo en las Comunidades estudiadas que son tres, entre alrededor de cincuenta comunidades Shipibo-Conibo. El inventario nos permitió caracterizar las tres comunidades con respecto a su relación con el hombre ("vana rao", "nahue rao", "nii rao"). Pero lo podríamos hacer con otros caracteres como los usos terapéuticos. Esas caracterizacines hacen tipología de comunidades con los "rao", como se hace clásicamente con otros caracteres culturales (cerámica, idioma) y antropológicos (hemotipología). Esas típologías pueden ser medios para estudiar la Etnología y la Historia del Ucayali, investigar los intercambios intra e interétnicos.

Los autores quisieran dar gracias al Dr. Sastre y al R.P. Soukup por las determinaciones botánicas, al Dr. Friedberg por sus comentarios de indole etnobotánico y al Pr. d'Ans por las discusiones lingüísticas. 


\section{INVENTARIO DE LOS “RAO" DE LOS SHIPIBO-CONIBO DEL UCAYALI}

\section{ACANTACEAS}

Justicia pectoralis, (80-14), flor blanca, Caimito, cultivado spb. "marica mishquitinin rao": marica es un nombre genérico para hierbas de propiedades diferentes, mishquiti es anzuelo.

Terapéutica: $1^{\circ}$ antes de la pesca o de la caza se ahúman las hojas en agua hirviente y se sudan manos y brazos,

$2^{\circ}$ de las hojas machacadas se hacen supositorios que se ponen a los niños flojos y haraganes para que se vuelvan activos.

Justicia sessilis, (80-13), tiene olor de apio, Caimito, cultivado spb. "caanena".

Terapéutica: $1^{\circ}$ úlceras intestinales, se toma en refresco después de hervirla, $2^{\circ}$ para hacerse curandero, se la toma después de dietar.

Justicia sp., (80-30), pequeña flor azul, olor de cumarin o limón, Caimito, cultivado; spb. "rimon ininti": olor de limón,

"chono ininti": olor del pájaro "chono" (Hirundinaea), "antes cuando esos pajaritos eran como la gente ellos se curaban con esa planta".

Terapéutica: cura de la diarrea, vómitos y cólicos; se hace infusión de las hojas y se serena para tomar. Se puede tomar puro.

Sanchezia ovata, (81-41, 81-42), hierba de 1 a 2 metros de alto, corola amarilla, bractea roja. Betijay, purma, bajeal.

spb. "savan"

Terapéutica: resfríos y reumatismos, no se toma, se hierven las hojas en olla de barro y cubriendo al paciente con una frazada se le da baños de vapor; se aplican las hojas maceradas en las articulaciones adoloridas.

sobre lomas,

81-24), arbusto de 1 metro, flor coposa morada, S. Rosa Agu., monte

spb. "ino paviqui", ino=tigre, paviqui $=$ oreja

Terapéutica: resfrio, se hacen hervir las hojas y se respira el humo hasta que se suda.

\section{AMARANTACEAS}

Alternanthera sp., (80-25), hierba sogante de hojas rojizas, Caimito, purma, spb. "poi mashe", poi=hoja, mashe=achiote,

"poa iona rao", poa=sacha papa (papa silvestre), iona=fiebre.

Terapéutica: fiebre y dolor de cabeza, se la machaca y se la toma o lava la cabeza. Pfaffia irisinoides (80-2, 81-80), hierba leñosa en la base, pequeñas espigas blancas, Caimito, Betijay, sembrado, spb. "marosa".

Terapéutica: curanderismo, "seis días se toma una media taza, se descansa seis días y después se toma el Ayahuasca que tiene el máximo efecto, hay Doctores que viene y. te enseñan todo, hay que dietar una semana".

\section{ANACARDIACEAS}

Tapirira sp., (80-3), árbol de 15 metros, tronco espinoso, su fruta es colorada, anaranjada y fragante, Caimito, purma (y monte?) 
spb. "atsan tita", atsan=yuca, tita=madre.

Terapéutica: para engordar, su corteza y raíz en agua tibia.

\section{ANONACEAS}

Annona sp., (81-29), árbol, fruta comestible, S. Rosa Agu., purma, spb. "repote rao", repote=echar en la nariz, nombre común: "hicofa".

Terapéutica: "resfrío, se cocinan su corteza y hojas, se huma y recibe su humo".

\section{APOCYNACEAS}

Bonafousia longituba, (80-42, 81-30), arbusto 1,5 metros, flores amarillo-pálido, lechosos, S. Rosa Agu., purma, bajeal;

spb. "nane repote", nane=huito (Genipa americana), repote=echar en la nariz, nombre común: "cocha sanango".

Terapéutica: a) dolor de muela, su leche se aplica sobre la muela;

b) anticonceptivo, se raspa su corteza, se hierve, se toma tres veces, sirve para siempre.

Bonafousia sananbo, árbol de hasta 15 metros, flores blancas;

S. Rosa Agu., purma (monte?)

en S. Rosa Agu. se llama "sanango".

Terapéutica: se usa para reumatismos, dolores del cuerpo y para dar fuerza física y mental; se saca su raíz, se raspa y se diluye con agua y se bebe; debe dietar 8,15 ó 30 días antes (sin sal, azúcar, manteca y mujer).

Bonafousia tetrastachys (81-40), árbol de 2 metros, flores blancas, Betijay, purma (bajeal),

en Betijay se llama "cocha sanango".

Terapéutica: reumatismos, su raíz se raspa, chapeada, y se mezcla con trago, se toma.

Bonafousia undulata, (80-41), arbolito de 5 metros, flores moradas, S. Rosa Agu., purma.

spb. "muca pari", muca=amargo; nombre común: chiri sanango.

Terapéutica: como el Bonafousia sanaho.

Thevetia peruviana (81-33), arbolito, flores amarillas, S. Rosa Agu., cultivado, sus semillas sirven de adorno, la planta es ornamental; spb. "tapote".

\section{ARACEA}

spb. "taia", (77-20), hierba, caimito, purma

sirve para cazar el motelo.

Dracontium sp. (81-48), hierba de 1 metro, tallo con bandas grises y blancas como la piel del jergón, Betijay, monte "donde hay jergones".

Terapéutica: "se azota con el tallo y el jergón (o el shushupi) no va a picar", sus papas machacadas se ponen en emplasto en la herida del jergón.

\section{ASCLEPIADACEAS}

(80-17), pequeña soga, Caimito, purma

spb. "mashi iman rao", mashi=playa, iman=hormiga 
"su resina se pone sobre chupitos y comezones y el pus sale", también actúa sobre conjuntivitis infecciosas.

\section{BIGNONACEAS}

Macfadyena unguis-cati (81-31), soga que sube con sus "garras" o "uñas", S. Rosa Agu., purma

spb. "cashi tae": cashi=murciélago, tae=garras o uñas, nombre común: uña de gavilán.

Terapéutica: para lavar heridas, las hojas se ponen en agua tibia.

(81-78), sogita, Betijay, purma

spb. "inin $\operatorname{tani":~inin=olor,~} \operatorname{tani}=$ un poco.

Terapéutica: dolor de cabeza, se la chapea en agua y pone con un trapo sobre la cabeza.

spb. "binan haca rao".

(80-36), hierba, soga, Caimito, Junín Pablo, purma

\section{BORRAGINACEAS}

Cordia (80-39), arbusto 2 metros, con bolsitas a los nodos de las hojas, Junín Pablo, purma, frutas comestibles (?)

spb. "capa uboshco": capa =huaihuashi (un especie de ardilla), uboshco=testículos.

Terapéutica: $1^{\circ}$ se raspa su corteza y se pone gotas de resina en el ojo, tres veces, para no tener sueños, no dormir",

$2^{\circ}$ "se usa la corteza que hierve, se la toma para limpiar el estómago, produce vómitos y vuelve bizarro a la gente y rápidos como las ardillas".

Heliotropium angiospermum (80-31), hierbita con flores azules en espigas, Caimito, purma

spb. "hivuin rao": hivuin=raya.

Terapéutica: se machacan las hojas y aplican el jugo en las heridas hechas por la raya.

\section{CARYOCARACEAS}

Anthodiscus Klugii (77.32), árbol $5 \mathrm{~m}$., hojas trifoliatas, frutas verdes $5 \mathrm{~cm}$. de diámetro con puntos blancos; Caimito, Betijay, bajeales y orillas de lagunas, spb. "au", nombre común: "tamara".

Terapéutica: $1^{\circ}$ para mal de estómago; se raspa su corteza o su fruta, se pone en agua y se toma,

$2^{\circ}$ para chupos: se raspa su fruta y se pone sobre el chupo, arde un poco.

\section{CHENOPODIACEAS}

Chenopodium ambrosoides, (77-36, 80-23), hierba de mucho olor, pequeñas flores verdes; Betijay, Caimito, S. Rosa Agu.; cultivada;

nombres shipibo y común: "paico".

Terapéutica: $1^{\circ}$ uso externo: sobre chupos, machacada en agua caliente (Betijay); contra hinchazón (de golpe), con sal y tabaco en agua caliente;

$2^{\circ}$ uso interno: contra lombrices, se la machaca y toma su jugo en agua fresca. 


\section{COMPUESTAS}

Bidens pilosa, (80-12, 81-57), hierba, Betijay, Caimito; purma spb. "shobi isa sheta": shobi=hierba, isa = pájaro, sheta=diente.

Terapéutica: dolor de muelas, hojas y tallo se aplican sobre el diente; dolor de cabeza, en emplasto alrededor de la cabeza.

Tagetes sp. (77-31), hierba, Caimito, cultivado;

spb. "pisi sisa": pisi=que huele feo, sisa $=$ rosa (nombre quechua).

Terapéutica: para pesadillas, infusión de las hojas, para niños y adultos, se toma y lava la cabeza.

\section{CONVOLVULACEAS}

Ipomea sp. (81-53), hierba sogante, Betijay, purma

spb. "pish pish", "el pájaro que dice pish pish" (genre Tachyphonus, fam. Thraupidées), se curaba con esta planta".

Terapéutica: vomitivo, las hojas machacadas en agua, produce intensa mareación que se contrarresta con azúcar o chapo de plátano; es bueno para el hígado.

\section{CRASSULACEAS}

Kalanchoe pinnata (81-50), hierba suculente, $50 \mathrm{~cm}$. de alto; Betijay S. Rosa Agu.; cultivado.

spb. "tobi rao", tobi=lisiado.

Terapéutica: dolor de cabeza, fiebre: se machacan las hojas frescas, las ponen en agua y se baña con el agua.

\section{CYPERACEAS}

Scleria mitis (80-10), hierba con hojas filudas en los bordes que pueden cortar fácilmente; Caimito; purma

spb. "nepa", nepa $=$ cortar.

Terapéutica: "se cocina, se toma cuando hay chupos adentro del estómago"; (para las personas que están embrujadas?).

Fuirana sp. (81-66), hierba, tallo con sección triangular; Betijay, cultivado.

spb. "uashmon uaste", uashmon=algodón, uaste= piri piri.

Terapéutica: $1^{\circ}$ su papa raspada se pone sobre el ombligo del bebe, como algodón; $2^{\circ}$ las mujeres toman el jugo de la papa para ser buenas hiladoras y tejedoras de algodón.

Heleocharis sp. (81-68), hierba, sección triangular, "septé" e involucrado; Betijay; cultivado

spb. "bohue uaste", bohue es el nombre del pescado "boqui chico", uaste= piri piri. Terapéutica: para la pesca, se soba la flecha con su papa antes de pescar el "bohue" Cyperus sp. (81-67), hierba, sección triangular; Betijay; cultivado. spb. "repoti uaste", "repoti(e)"=echar en la nariz, uaste=piri piri.

Terapéutica: "se echa el jugo de la papa en la nariz del hombre que no quiere trabajar".

Cyperus sp. (81-69), hierba, papas blancas; Tombuya; cultivado spb. "shua uaste", shua =gordo.

Terapéutica: para engordar, a los niños se les administra el jugo de las papas con leche materna y "se mantienen muy gordos y no se enferman; a los adultos les proporciona gordura y fuerza, hay que dietar (sin sal y dulce por quince días)". 
Cyperus sp., hierba, Betijay; cultivado spb. "regalo uaste", regalo= palabra castellana.

Terapéutica: se usa para tener buena suerte en negocios, se raya la papa y se aplica a los cabellos y manos:

Cyperus sp. (81-70), hierba, hojas grandes y cortantes; Tombuya (bajo Betijay); cultivado

spb. "tobi uaste", tobi=lisiado

Terapéutica: para golpes y lisiados, se ponen las papas rayadas (se toma?)

Cyperus sp. (81-36), hierba; S. Rosa Agu.; cultivado

spb. "uaste", no más.

Terapéutica: para pescar, (por ej. el paco) 3 días sin que lo toca el sol, después se machaca y raspa sobre el cuerpo.

\section{EUPHORBIACEAS}

Alchornea castaneifolia (81-77), árbol $5 \mathrm{~m}$, apariencia de un sauce, hojas alternadas, dentadas; Betijay, en la playas y terrazas cerca del río.

spb. "ipo roni", ipo=carachama, roni=boa; nombre común: "ipo ruru".

Terapéutica: vomitivo, tos ferina, frío, resfrío (con aguardiente), diarrea; se raspa su corteza, se cocina y concentra el jugo, se le toma.

Euphorbia sp. (80-18), hierba, $30 \mathrm{~cm}$. pequeña flor blanca; Caimito; purma.

spb. "ai curo", ai=gaviota, curo=gris.

Terapéutica: "para ser cantor, té en agua caliente" "la toman los aprendices de medicina vegetal y de curanderos, mejora la visual en la mareación, se dieta sal"; "lo añaden para mejorar la voz al cantar los icaros y taquinas".

Euphorbia sp. (80-28), hierba diminuta trepadora; Caimito; crece en las calles y cerca de las casas,

spb. "jima shian rao", jima shian=hormiga chica.

Terapéutica: su látex blanco en aplicación externa sobre chupos y heridas.

Hura crepitans (80-44), árbol grande, tronco espinoso; S. Rosa Agu.; monte y purma. spb. "ana"; nombre común: "catahua (negro)".

Terapéutica: $1^{\circ}$ su resina (cáustica) sirve para curar uta y úlceras; también para tumor y picaduras de viboras.

$2^{\circ}$ su resina para envenenar el pescado.

Muy tóxico y peligroso.

Jatropha curcas (77-27), arbusto; Caimito, cultivado

spb. "pion mis", nombre común: piñón.

Terapéutica: $1^{\circ}$ externo, su resina sobre las heridas;

$2^{\circ}$ interno: hojas en té para diarreas,

semillas asadas para producir vómitos y diarreas.

Jatropha gossyfolia (77-28), arbusto, Caimito, cultivado

spb. "pion huiso", huiso=negro.

Terapéutica: como el "pion mis".

Mabea (77-2), arbusto (árbol?), Caimito; purma o monte spb. "camparo".

Terapéutica: caza, "para tirar bien las flechas a los animales". 


\section{GRAMINACEAS}

\section{spb. "huahui poi" poi=hoja.}

Terapéutica: "hojas machacadas en agua caliente echada en las manos" o "se hierven las hojas y encima de ese vapor se ponen las manos", proporciona mayor habilidad manual: "para hacer la canoa, pinturas de la cerámica", mejora el pulso, también para la caza".

\section{IRIDACEAS}

Eleutherine bulbosa (80-6), hierba, flores blancas, papas rojas; Caimito, Betijay; cultivado

spb. "jașin uaste": jasin=paujil (pájaro), Mitu mitu, uaste=piri piri, sus hojas parecen como las de los otros piri piri que pertenecen a la familia de las Cyperaceas. Terapéutica: las papas raspadas sirven para las heridas hemorrágicas.

\section{LABIADAS}

Hyptis suaveolens, (80-9), Caimito, cultivada spb. "oite poco" o "tee poco", poco=comida.

Terapéutica: para ser cazador, se pone en agua caliente, se lava los brazos.

Hyptis sp. (R) (81-65), hierba, $50 \mathrm{~cm}$., olor de Hyptis pero hojas redondas como Ocimum; cultivada.

spb. "tipo".

Terapéutica: vomitivo, dolor de estómago, en té.

Ocimum, son hierbas de olor cultivadas en todas las comunidades, en castellano se llaman "albahaca", los Shipibo-Conibo las llaman a veces "arbaha", hay variás especies semejantes y difíciles de distinguir.

Ocimum americanum (80-37); hierba, $50 \mathrm{~cm}$., Caimito

spb. "vero rao", vero $=$ ojo.

Terapéutica: $1^{\circ}$ con ella el curandero abanica al enfermo;

$2^{\circ}$ heridas en la cabeza producidas por zancudos e isangos, se machacan sus hojas y el jugo se pone sobre las picaduras.

Ocimum sp. (81-64), hierba, $50 \mathrm{~cm}$., Betijay

spb. "huidoro" o "vero rao".

Terapéutica: $1^{\circ}$ se baña para botar la saladera (con manchari uaste)

$2^{\circ}$ para bañar al bebe;

$3^{\circ}$ como un té, "para el gusto".

Ocimum gratissimum (80-26); hierba; Caimito

spb. "mai cahua rao"; mai=tierra, cahua=que esta alrededor; es el nombre de un ave de rapiña, fam. Accipitrideas, que grita "mai cahua", es de mal agüero; los mestizos lo llaman "ave huancahui".

Terapéutica: dolor de cabeza, fiebre, cuando se siente mal, en agua fría, para lavarse la cabeza y bañarse;

"se usa haciendo patarashca y se aplica al cuerpo en forma de frotaciones" "se le hace tomar tres veces en agua tibia, es bueno para los vómitos y controla el dolor de estómago".

Ocimum micranthum, (77-38); hierba, $30 \mathrm{~cm}$.; Caimito; spb. "arbaha". 
Terapéutica: mal aire, dolor de cabeza, se toma y después sobre la cabeza. Ocimum u otro género (81-26); hierba, S. Rosa Agu.

spb. "tipo", se llama como la muestra (81-65) pero es diferente, con hojas dentadas. Terapéutica: dolor de estómago, se cocina como un té.

\section{LEGUMINOSAS}

Calliandra angustifolia (81-39); arbolito, 5 m.; estambres rojas; S. Rosa Agu; crece en las orillas de los ríos

spb. "semei"; el nombre común es bobinsana.

Terapéutica: resfrío, dolor de cuerpo, para tener fuerza, se hierve su corteza, se toma o se baña con ella.

Desmonium canum (80-34); hierba; Caimito; purma spb. "haca betonco shobi", haca=vaca, betonco=frente, shobi=hierba.

Terapéutica: "las hojas secas machacadas en polvo se ponen en las heridas"; "se saca la hierba y se machaca con todo su palito, luego se hierve en una olla grande hasta sacar sólo media botella; se le da a la mujer medio vaso pequeño en ayunas, antes del almuerzo, de la comida y al acostarse los 6 primeros días de su regla y queda estéril el resto de su vida, no la malogra ni produce ninguna enfermedad".

Erythrina sp. (81-61); árbol, $20 \mathrm{~m}$., flor roja, rachis con 3 hojitas: Betijay purma (y monte?)

spb. "Caasho", el nombre común es "hama sisa".

Terapéutica: vomitivo, se raspa su corteza y se toma en pequeña dosis; se usa también para bajar la fiebre y para quemadura de arco.

Rynchosia sp. (80-29); sogita; Caimito.

spb. "hoshi ino seya", hoshi=colorado, ino=tigre, seya=comezón; la leyenda dice que el tigre colorado (Felis puma) se curaba con esta hierba y que después aprendió a usarla para aliviarse de las comezones y picazones, cuando la piel presenta ronchas, salpullidos o intoxicaciones pririginosas.

Terapéutica: dermatitis piógenas, eczematidas; se saca sus hojas y se hace "patarashca", luego se saca la humedad exprimiendo esas hojas calientes, el líquido se aplica externamente a la piel.

Tacbigalia sp. (77-34); arbusto, Caimito, purma (cf "rinoro" Cashibo) spb. "uapa".

Terapéutica: mal de cabeza, se pone alrededor de la cabeza.

(81-34); arbusto, hojas compuestas de 7 foliolas; S. Rosa Agu.; purma spb. "capetan huarasca": cape=lagarto, huarasca=barbasco.

\section{LOGANIACEAS}

Strychnos (77-40); soga; monte; Caimito

spb. "vona muca": vona=isula, "la isula es un insecto de color negro cuya picadura es muy dolorosa, un niño puede morir con tres o cuatro picaduras de isula; cuando este insecto muere crece de su cuerpo el tamshi que es una soga muy resistente que usan para fabricar muebles aireados, canastas y como amarras de las casas".

Terapéutica: el palo se mastica para el mal de diente.

Oryctanthus alveolatus (80-11); leñosa, parásito de los árboles y frutales; soguea y los 
seca hasta matar, crece cuando cierto tipo de pájaro deja su deposición sobre árboles y de ahí crece el "shanen vana".

Frutales, purma (monte); Caimito

spb. "shanen vana": shanen=pájaro, vana=sembrado; nombre común="suelda con suelda".

Terapéutica: para golpes, contusiones, fracturas; se machacan sus hojas, se las aplican y amarran sobre la quebradura del hueso; "para aprender a sobar a los lisiados: se cocina la planta, se pone las manos sobre el humo que sube, se limpian las manos cada mañana 5 veces"; algunos la usan para la función hepato-biliar.

Phtirusa sp. (80-21); misma ecología que el Oryctanthus; Caimito

spb. "shanen vana jacon", jacon=legítimo.

spb. "shanen vana".

(81-52); id.; encontrado en Betijay

(80-16); soguita; purma; Caimito

spb. "quyosh rao", quesha=boca, yoshe=torcer.

Terapéutica: es anti-emético, calma los cólicos y calambres, se toma como té, en infusión en agua hirviente cinco minutos.

\section{MALVACEAS}

Malachra capitata (80-19); hierba que alcanza $2 \mathrm{~m}$. de alto, flores amarillas en racimos; cultivada; Caimito, Betijay, S. Rosa Agu.

spb. "malva" o "marica"; nombre común: "malva".

Terapéutica: dolor de cabeza y fiebre, se machacan sus hojas, las ponen en agua (fresca o tibia), a veces se agregan hojas de piñon (Jatropha sp.), para refrescar la cabeza; para mal de estómago y de barriga, diarrea, se toma; "para obediencia, a tu hijo quien te va a obedecer y a hacer caso de lo que vas a decirlo, la toma; para lavar ropa.

Sida sp. (80-38); hierba, flores amarillo-pálido; purma; Caimito

spb. "shobi shodish", shobi=hierba, shodish=dura.

Terapéutica: se la machaca en agua, (se mezcla también con aguardiente), se lava el pelo, para hacerlo crecer largo, o para que no se caiga.

Sida sp. (80-49); hierba; flores amarillas; purma; S. Rosa Agu.

spb. "matsoti"= barrer; nombre común: "ñuc ñuc pichana".

Terapéutica: "faltando un mes para dar a luz, la señora la toma", también para fiebre, se baña en la planta machacada en agua.

\section{MELIACEA}

Carapa sp. (80-7, 77-35); árbol, $20 \mathrm{~m}$.; purma y bosque; es árbol maderable; Caimito spb. "shoro".

Terapéutica: dolor de estómago, se toma su corteza en agua fría y se vomita; también se usa su corteza en patarashca o emplastos para abscesos.

\section{MENISPERMACEAS}

Cissampelos sp. (77-41); soga, flores diminutas; purma, Caimito spb. "vona muca", cf. Strychnos 
Terapéutica: "mal de diente", se raspa y pone en el hueco.

Cissampelos sp (81-82); flores diminutas en racimos, "soga", huayos como uvas; "purma"; Betijay

spb. "reesho toscan", reesho es el moco de la nariz; toscan=en racimos o abundante. Terapéutica: se hace té en agua hirviente, para la tos e inflamación de garganta; las hojas hervidas se aplican externamente en la nariz y fosas nasales.

(81-28); soga leñosa; monte; S. Rosa Agu.

spb. "nishi" = soga (no más); nombre común: "abuta".

Terapéutica: "resfrío y dolor de cuerpo, se la pica, la hierve 12 horas, y se la toma de las 6 de la mañana a las 5 de la tarde".

\section{MONIMIACEAS}

Siparuna sp. (80-43, 81-44); hierba de hasta $2 \mathrm{~m}$., sus frutas maduras son rojas, semillas con arillos, planta olorosa; purma; Betijay

spb. "ioshin bia", ioshin=espíritu, bia=cogido, "ha cogido el espíritu".

Terapéutica: malos sueños, fantasmas, se "chapean" sus hojas y se baña.

\section{MORACEAS}

Brosimum uleanum (81-38); árbol 30 m.; monte; S. Rosa Agu.

spb. "vašho", nombre común: "manchinga".

Terapéutica: reumatismos, mal de estómago, purgante, se toma su resina blanca.

Brosimum sp. (81-62); árbol, 30 m.; fruta: drupa; monte; Betijay

spb. "shochi rao", shochi=pecho.

Ficus sp. (81-46); árbol grande $(30 \mathrm{~m}$.$) , cáscara gris, madera roja, látex blanco, hojas$ pequeñas alternadas; monte; Betijay

spb. "shona" = renaco.

Terapéutica: "cuando el hombre es pálido: se raspa su corteza, se la cocina; se forma un líquido que parece miel, se la toma y el enfermo bota todo"; también ayuda a la recuperación de fracturas, lisiados, hernias.

\section{MYRTACEA}

Betijay.

spb. "hivui vuero", hivui=raya, vero $=$ ojo.

Terapéutica: "se raspa la carne que cubre su semilla y se la pone sobre la muela".

\section{OENOTERACEA}

Ludwigia (80-22); hierba, flor amarilla; purma, playas, caminos húmedos; Caimito (también se ve en Betijay pero parece que no se utiliza),

spb. "caya nari rao", caya=sombra o espíritu, caya nari=pájaro (Leucopternis cayanensis, fam. Accipitridés), "pájaro que incuba dentro del agua, sus huevos se incuban protegidos o resguardados por las carachamas que rodean a los huevos hasta que revientan".

Terapéutica: lo usan para volverse buenos pescadores-cazadores, se toma como un té, también se hierven las hojas y se recibe el vapor en las manos; "honi mucha"=hombre cazador. 


\section{UMBELIFERAS}

Eryngium foetidum $(77-29,80-8)$; hierba $(30$ a $40 \mathrm{~cm}$.) muy comúnmente cultivada; Caimito, Betijay;

spb. "as̈he", nombre común: "sacha culantro".

Terapéutica: Betijay, "se la toma cuando se tiene alta fiebre, ya sea cocinado o como un té, con la hierba luisa, también en el caldo con la carne".

Caimito: 1. "se la machaca y se lava la cabeza, dolor de cabeza y gripe";

2. "para el estómago y como vomitivo, té en agua caliente",

3. "para bronquitis, en té",

4. "se come como legumbre".

\section{PASIFLORACEAS}

Passiflora sp (81-75); sogita, purma, Betijay;

spb. "resenebi" o "rešhenebi", rešhe= moco.

Terapéutica: fiebre, se baña la cabèza y el cuerpo en agua tibia.

Passiflora sp. (80-5); es una soga (leñosa) que abunda en las tahuampas y orillas de las cochas, soguea y tiene frutas semejantes a la granadilla que son comestibles para los humanos, los peces los comen, se usa para anzuelar la gamitana; purma; Caimito; spb. "chupi ananti".

Terapéutica: se hacen "patarashcas" de sus hojas que se aplican calientes sobre el abdomen cuando hay estreñimientos o "bultos", dolores abdominales e indigestiones; no se toma, es de sabor muy amargo.

Passiflora sp (81-51); soga leñosa, diferente de 80-5; purma; Betijay; spb. "chupi ananti".

Terapéutica: cf. 80-52.

PHITOLACACEAS (o Fitolacaceas)

Petiveria alliacea (77-1, 80-47); hierba que se cultiva mucho, Caimito, S. Rosa Agu., Betijay

spb. "buen"; "nia buen", ("nishi buen" es el "ajo sacha"), su nombre común es "mucura".

Terapéutica: contra la gripe, en la nariz, para la caza (y la buena suerte): se "chapean" las hojas en el agua, se baña todo el cuerpo, se la toma también, se pone en la nariz (a los perros también); se aplica su corteza sobre granitos, duele pero se van y. se rejuvenece la piel.

\section{PIPERACEAS}

Piper sp. (80-48); arbustito; purma; S. Rosa de Agu.; spb. "matico"; nombre común: "cordoncillo".

Terapéutica: para reumatismos se baña; interno para riñones; se toma con limón verde y azúcar para dolor de "desmante".

Piper sp. (81-32); arbustito muy semejante al precedente (80-48); purma; S. Rosa de Agu.;

spb. "ioto coti" o "ioto conti"; "matico"; "cordoncillo".

Terapéutica: vendaje exterior sobre el hígado; sus hojas sirven para teñir los dientes de color negro.

\section{DIGITALIZADO EN EL CENDOC - CAAAP}


Potbomorpbe peltata (81-56); planta herbácea con hojas grandes en forma de corazón; purma; Betijay;

spb. "chinshon"; común "santa maría".

Terapéutica: estómago, se toma en agua caliente como un té; el jugo del tallo se pone en el ojo del niño para su vista.

\section{POLYGONACEAS}

Polygonatum sp. (81-54); soga; purma; Betijay

$\mathrm{spb}$. "tae maia shanca rao", tae = pie, maia =que es redondo o que da vuelta como un remolino, shanca $=$ piedra dura como acero.

Terapéutica: sus hojas se machacan, se cocinan y se echa la de cocción sobre la cabeza (no se toma).

Triplaris sp. (80-4); árbol (20 m.), tronco espinoso; en este árbol suelen vivir miles de hormigas "tangaranas" carnívoras que pican duro; purma (monte?); Caimito.

spb. "hanin"; común: "tangarana".

Terapéutica: se hace hervir su corteza en agua, queda como un miel que se toma contra la fiebre interior y diarrea.

\section{PORTULACACEA}

Portulaca pilosa (80-40); planta herbácea baja con flores regulares de color carmín; crece sobre las playas arenosas.

Nombres: en Imiría se llama "sisa" (que significa flor en quechua); en Pucallpa se llama "flor de las once".

Terapéutica: "sus hojas se soban sobre las piernas del bebé para que ande más rápido".

\section{RUBIACEAS}

Diodia sp. (80-24, 81-81); planta medio leñosa; purma; Caimito, Betijay spb. "ai pana".

Terapéutica: "estómago, se toma como un té, se vomita y limpia todo y después se lava la cabeza"; "es antiflatulento, lo usan contra el dolor de estómago en forma de té"; "se 'chapean' las hojas con lo que se enjuaga la ropa, es oloroso".

Rudgea sp. (77:37, 80-15); árbol de $10 \mathrm{~m}$., frutas de $2 \mathrm{~cm}$. de largo; purma; Caimito spb. "mesque".

Terapéutica: "con su huayo se anzuela la palometa"; "dolor de barriga, se aplica sobre la barriga y se inhala el vapor".

Psychotria sp. (81-49); pequeño árbol, hojas con excrecencia de la nervura; crece cerca del agua; Betijay

Nombres: spb. "cahua", común "chacruna".

Terapéutica: se agrega al Banisteriopsis en el "ayahuasca"

(80-45); purma; S. Rosa de Agu.

spb. "oichca rao", "nasheti rao".

Terapéutica: fiebre, se baña.

(81-72); purma; Betijay

spb. "iscon ratonco", iscon=paucar (orn Icteridae), ratonco=rodilla.

Terapéutica: resfrío, reumatismo, se cocina, se ahúma todo el cuerpo y se sana. 


\section{SAPOTACEA}

(80-27); árbol de $10 \mathrm{~m}$., latex blanco; purma; Caimito.

Nombre: en Caimito lo llaman "sucuba", (la muestra es insuficiente para identificación: podría ser también Himatanthus sucuuba, Apocynacea, cf. 81-99).

Terapéutica: "la leche se pone en chupos con boleta de pus", "sobre la hinchazón que no madura: se seca la planta, se la bota y se pone otra fresca".

\section{SCROFULARIACEAS (o Escrofulariaceas)}

Scoparia dulcis (80-33); hierba de 30 a $50 \mathrm{~cm}$. de alto; purma (cultivada ?); Caimito, Betijay.

Nombres: spb. "vata matsoti", vata=dulce, matsoti=barrer; el nombre castellano es "temelito", también se llama "ñucñu pichana" que parece de origen quechua.

Terapéutica: "mal de estómago", se toma toda la planta en agua tibia; fiebre interior, en refresco; en heridas; se pone directamente su jugo sobre la herida.

\section{SOLANACEAS}

Cyphomandra sp. (81-37), árbol $5 \mathrm{~m}$., flores amarillas, S. Rosa, purma, olor desagradable.

$\mathrm{spb}$. "chiquish payati", chiquish=pereza, payati=abanicar; nombre común: "arco sacha".

Terapéutica: dolor de cabeza con fiebre, las hojas con otras plantas: "pisi sisa", hojas de "malva" y de limón para refresco, también para bañarse.

Solanum grandiflorum (77-30); arbolito de no más que $10 \mathrm{~m}$., espinoso, con hojas grandes y espinosas, frutas maduras de color negro; Caimito, Betijay.

Nombre spb.: "popo ani", popo designa plantas del género Solanum, ani=grande. Terapéutica: "se pone su huayo sobre el chupo, si el chupo no se revienta pronto no hay que cortar, se madura el pras".

Solanum sp. (81-60); hierba de $50 \mathrm{~cm}$. a $1 \mathrm{~m}$.; purma; Betijay.

spb. "popon sacha", sacha = silvestre o falso en quechua.

Se usa contra el dolor.

(81-59); hierba de $50 \mathrm{~cm}$; purma; Betijay.

spb. "samun rao", samun=insecto de color marrón (que vuela y suena parecido a la ronsapa, hay otro más chico de color celeste).

Terapéutica: "se baña para evitar chupos", (para inflamaciones locales, se usa en forma de patarashca).

\section{URTICACEAS}

Laportea sp. (81-25); hierba de 1m.; purma (cultivado?), Betijay.

Nombre spb.: "moe", común: "ishanga".

Terapéutica: se azota con la planta durante la sesión del vegetalista, arde.

Urera sp. (80-46); planta que alcanza $5 \mathrm{~m}$, apenas leñosa; purma; S. Rosa de Agu. Nombre spb.: "ishish moe", común "ishanga", "ishish es el nombre de cierto pez pequeño que tiene una lanceta que nos hiere si no se cuida".

Terapéutica: $1^{\circ} \mathrm{mal}$ de estómago: externo se aplica sobre la piel, arde; 
$2^{\circ}$ picadura de isula, se pega repetidas veces hasta que se calme el dolor, hay que dar, cuando se acaban sus espinas se coge otra planta;

$3^{\circ}$ calambres;

$4^{\circ}$ macerando su raíz lo toman para curarse de la brujería o del "daño de gentes"; ante cualquier sospecha de brujería lo toman fresco o hervido al acostarse y dieta sin sal.

\section{VERBENACEAS}

Verbena cf. brasiliensis, son hierbas de olor cultivadas en todas las comunidades, los Shipibo-Conibo los llaman "viribina" del castellano verbena.

(81-27), S. Rosa Agu.; contra la diarrea, en té;

(81-63), Betijay; contra la diarrea, en té; para que las mujeres no dan a luz, 3 veces al mes, en té.

\section{VITACEA}

Cissus erosa (80-35); sogita; purma; Caimito

spb. "samun tao" cf. 81-59, Solanacea.

Terapéutica: hinchazón, se pone en agua tibia y se lava la hinchazón.

\section{ZINGIBERACEAS}

Costus of. cylindricus (80-20); hierba de hasta 1 a 2 m.; purma Caimito, Betijay.

Nombres: spb. "bocosh taco", cast. "caña agria" o "cañagre", se llama también "sacha huiro" de origen quechua (sacha=silvestre, huiro=manteca).

Terapéutica: $1^{\circ}$ "fiebre interior, intestinal, se pela el palo, se machaca en agua fría, se la toma hasta vomitar";

$2^{\circ}$ "tos seca": se pela su corteza, se chupa su jugo como caña de azúcar, se toma y hay que expectorarla a mediodía, pequeña mareación";

$3^{\circ}$ "lo usan como antiinflamatorio del aparato digestivo y de higiene ginecológica; se saca la planta joven en retoño y se pela, se descascara el tallo que se corta en pequeños pedacitos y se macera, se le saca el jugo, tiene bastante jugo, es como una caña; se da una copa 3 ó 4 veces al día";

$4^{\circ}(\mathrm{R})$ "es una cañita gruesa que se usa en emplastos con su propia agua para bajar la fiebre y refrescar el abdomen y la cabeza".

2 m.; purma; Betijay.

?; muy parecido al Costus (80-20) pero con flor amarilla, hierba de 1 a

Nombre spb.: "iaishin shequi", iaishin=carachupa, shequi=maíz.

Terapéutica: se raspa su tallo y toma su jugo como vomitivo.

\section{PTERIDOFITA}

(81-55); 'un pequeño helecho que sirve de "puzanga"; epífita; monte; Betijay; "para puzanguear: se macera con agua, se baña manos y se sierre la mano de la chica".

Plantas cuyas familias no pudieron ser identificadas todavía (por el numero de berbario):

(81-47), nbre. spb. "pemosh tani", tani=un poco, pemosh=plumita de ave, Betijay; ronchas: la piel sale, se muda. 


\section{CUADRO}

Números de "rao" en cada Comunidad y de cada Categoría:

- Cultivadas: "c"

- De Purma: "p"

- De Monte: "m"

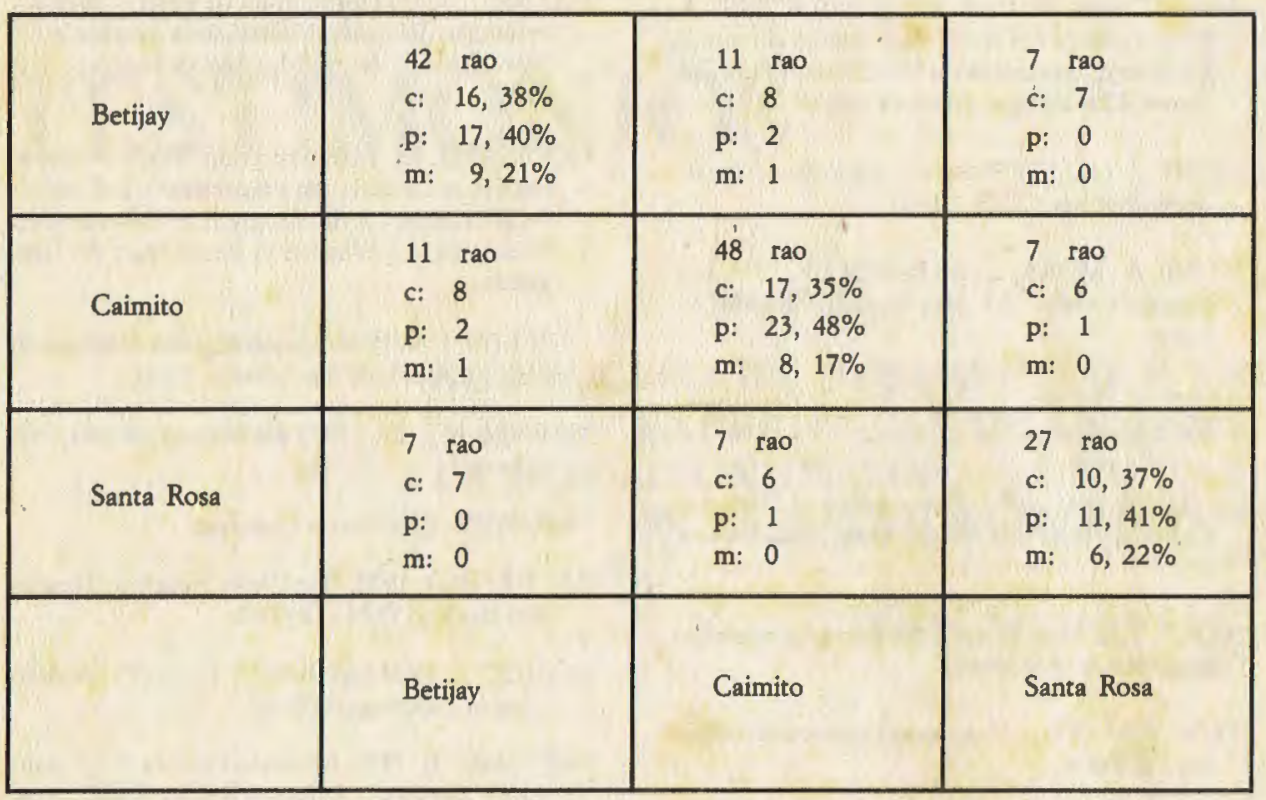

(81-58) "nivi tata", nivi=nieblina ("parecido a la nieblina"), hierba, monte, Betijay; dolor de estómago, se la "chapea" y soba sobre el estómago (no se toma).

(81-71), "seia tani" (cf 81-74), seia=comezón; arbusto leñoso a la basa; Betijay; dolor de estómago y regula la menstruación, se toma su hoja como un té.

(81-73), "shochi rao", shochi=pecho (cf 81-62); arbolito de $5 \mathrm{~m}$., con hojas alternadas; monte; Betijay; diarrea y para vomitar: la corteza cocinada como un té o fresca chapeada en agua.

(81-74), "pushnon rao", pushnon=roncha; hierba Betijay; en heridas: se hace una patarashca y cuando ella está fría se le echa en la herida.

(81-79), "Lobues tani", tani=un poco; sogita; Betijay; dolor de estómago, "se le chapea en un embalse en agua, se le soba sobre el estómago".

(81-83) "nain nishi", nishi=soga; Betijay; "cuando se hincha nuestro cuerpo, se la cocina en agua hirviendo y se lava".

"cuma rao", hay una foto pero no hay muestra de herbario, es un arbustito de $1 \mathrm{~m}$., hojas de $20 \mathrm{~cm}$. de largo, papa de $10 \mathrm{~cm}$. de diámetro; monte; Betijay; "se toma su raíz, su papa, la raspa en agua (no se cocina), se toma con vomitivo y contra diarreas (no es contra lombrices)". 


\section{B I B L I O G R A I A}

CAMPOS, R, 1977. Producción de pesca y caza en una aldea Shipibo en el río Pisqui. Amazonía Peruana, 1:53, Lima.

CENTILIVRES, P. GASCHE, J. LOURTEIG, A. 1975. Culture sur brulis et evolution du milieu forestier en Amazonie du Nord-Ouest, Bull. Sté. Suisse d'Ethnologie, Numero spécial 75.

CHIRIF, A. (ed)., 1979. Salud y nutrición en Sociedades Nativas. CIPA, Lima.

CHIRIF, A., MORA, C., MOSCOSO, R. 1973. Los Shipibo-Conibo del Alto Ucayali, SINAMOS, Lima.

CHIRIF, A., MORA, C., 1977. Atlas de Comunidades Nativas, SINAMOS, Lima.

CONKLIN, H.C. 1954. The relation of Hanunoo Culture to the Plant World, These, Yale University.

CROAT, T.B. 1978. Flora of the Barro Colorado Island, Stanford U. Press.

D'ANS, A.M. 1982. L'Amazonie péruvienne indigène, Ed. Payot.

DE BOER, W.R., LATHRAP, D.W. Ethnoarchaeology, Columbia U. Press.

DE WET, M.J., HARLAN, J.R. 1975. Weeds and Domesticates, Economic Botany, 29:99.

EAKIN, L., LAURIAULT, E.L., BOONSTRA, H. 1980. Bosquejo etnográfico de los Shipibo-Conibo del Ucayali, Ed. I.P. Pastor, Lima.

FRIEDBERG, C. 1965. Des Banisteriopsis utilisés comme drogue en Amérique du Sud, JAIBA, XII, 9-12, p. 403-437, 550-594, 729-780.
FRIEDBERG, C. 1970. Analyse de quelques groupements de végétaux, dans "Echanges et Communication", Vol. II: 1092-1131.

GASHE, J. 1975. Horticultura de corte y quema y evolución del medio forestal en la Amazonía del Nor-Oeste, Jo. Société des AMéricanistes, LXII: 215.

GOUSSARD, J.J. Mémoire pour l'Ecole Pratique des Hautes Etudes (en préparation). Laboratoire d'Ecologie et Biogéographie- Montpellier, Université des Sciences et Techniques du Lan. guedoc.

GUILLEN, F.N, 1974. Lexico Shipibo. Maestría en Lingüistica, U. de San Marcos, Lima.

HARNER M.J. Ed., 1973 Hallucinogens and Shamanism.

HOLGUIN, Diccionario Quechua.

LATHRAP, D. 1970. The Upper Amazon, Thames and Hudson Publ., London.

LORIOT, J. HOLLENBACH, B. 1970. Foundations of Language, 6:43-66.

MEGGERS, B. 1971. Man and Culture in a Counterfeit Paradise, Aldine-Atherton Publ., New York

MORIN, F. 1973. Thése de troisiéme cycle, Université de Paris.

SASTRE, C. 1980. Considérations sur les critères de classification botanique, JATBA, XXVII: 2.

TOSI, J.A. 1960. Zonas de vida natural en el Perú, Instituto Interamericano de Ciencias Agrícolas de la OEA, San José, Costa Rica.

TOVAR, E.D. 1966. Vocabulario del Oriente Peruano, Universidad de San Marcos. 